\title{
The Precise Local Tumor Characteristics of Supraglottic Carcinoma: A Comparison between Clinical, Radiological and Pathological Findings
}

\author{
HESHAM NEGM, M.D.*; HESHAM FATHY, M.D.*; MOHAMED MOSLEH, M.D.*; \\ AHMED FARAHAT, M.D.*; GAMAL KANDIL, M.D.* and AMAL HAREEDY, M.D.** \\ The Departments of Otolaryngology Head and Neck Surgery* and Pathology**, Kasr El-Aini University Hospital, \\ Cairo University, Egypt
}

\begin{abstract}
Background: In most cases of supraglottic cancer the tumor has already involved more than one sub site including a broad surface of mucosa with asymmetric extension in both surface and depth. In order to achieve proper loco-regional control of supraglottic cancer while at the same time providing the best possible results regarding organ preservation, knowledge of accurate tumor extension is necessary. This is achieved by thorough clinical, radiological and post-operative pathological assessment.
\end{abstract}

Aim of the Study: Determine the accurate extension of supraglottic squamous cell carcinoma by whole organ sectioning and comparing it with radiological and endoscopic findings.

Material and Methods: This study included 36 patients suffering from Laryngeal carcinoma originating from the supraglottic larynx. Direct laryngoscopy was done for all patients under general anesthesia for detailed primary tumor assessment. Detailed radiological assessmentusing C.T with contrast was done. Detailed histopathological examination by whole organ sectioning was done for the laryngectomy specimen.

Results: Radiological assessment was superior to clinical assessment in detection of tumor extension. On comparing radiological and pathological assessment the percentage increase of invasion of the paraglottic space and strap muscles were the only variables that were statistically significant ( $p$ value $=0.025,0.001$ respectively). On comparing clinical and pathological assessment base of tongue, vallecula and pyriform sinus were found to increase significantly statistically by pathological assessment $(p$-values $=0.025,0.046,0.046$ respectively).

Key Words: Supraglottic - Squamous cell carcinoma - Clinical - Radiological - Whole organ sectioning.

Correspondence to: Dr. Hesham Negm, The Department of Otolaryngology Head and Neck Surgery, Kasr El-Aini University Hospital, Cairo University, Egypt

\section{Introduction}

THE exact evaluation of supraglottic cancer upon first time of diagnosis may be difficult to evaluate since in more than $75 \%$ of cases the tumor has already involved more than one sub site including a broad surface of mucosa with asymmetric extension in both surface and depth [1]

In order to achieve proper loco-regional control of supraglottic cancer while at the same time providing the best possible results regarding organ preservation, knowledge of accurate tumor extension is necessary. Clinical office based laryngoscopy and rigid endoscopic examination under anesthesia should answer several questions in staging of the tumor, however limitations lies in dealing with submucosal and deep tumor extension [2].

Imaging being considered as adjunct to physical examination provides valuable assessment of anatomic spaces difficult to objectively assess on physical examination or by endoscopy namely the preepiglottic space, paraglottic space and thyroid cartilage invasion, furthermore imaging provides information regarding the tumor volume and extra laryngeal extension and these are of great value in surgical planning for tumor resection [3]

Major discrepancies were observed between the information given by imaging, clinical and endoscopic assessment and the results obtained upon postoperative histopathological examination of the surgical specimen. These variations were reported as significant false positive and false negative in revealing invasion of the preepiglottic space, paraglottic space and thyroid cartilage [4] . 
In the present study we aimed to determine the accurate extension of supraglottic squamous cell carcinoma by whole organ sectioning and comparing it with radiological and endoscopic findings.

\section{Material and Methods}

This prospective comparative study was conducted on 36 patients suffering from denovo Laryngeal carcinoma originating primary from the supraglottic larynx with or without palpable cervical lymph nodes. Patients were recruited form the Outpatient Clinic of Otolaryngology Department Kasr El-Aini Hospital Cairo University. The study was performed during the period from May 2014 till Jan. 2016. Patients with distant metastasis, prior radiotherapy or radio chemotherapy, recurrent tumor, pathology other than squamous cell carcinoma and tumour originating from outside the supraglottic region were excluded from this study. Ethical Committee approval was granted before embarking on the study and a preformed consent was signed by each patient participating in the study. All patients were males ranging in age between 44 and 72 with a mean age of $56.88 \pm 7.01$. Out of the 36 patients, 34 were chromic heavy smokers and 5 were consuming alcohol.

\section{Pre-operative clinical assessment:}

Full otolaryngology history taking and physical examination including thorough neck examination for palpable cervical lymph nodes was done for all patients. Evaluation of the primary supraglottic tumour was done first in the outpatient clinic with both rigid $70^{\circ}$ telescopy and flexible transnasal laryngoscopy to assess provisionally the exact site and extension of the primary tumor. Direct laryngoscopy under general anesthesia for detailed primary tumor assessment and biopsy taking was performed as well. The sub sites examined for tumor extension included the vallecula, epiglottis, aryepiglottic fold, vocal folds, ventricles, anterior commissure, arytenoids, pyriform sinus, pharynx and tongue base was palpated.

\section{Pre-operative radiological assessment:}

Detailed radiological assessment of the larynx and the neck was done with C.T with contrast axial cuts with coronal and sagittal reconstruction. The same sub sites of the larynx that were assessed endoscopically were furtherly evaluated radiologicaly in addition to, other sub sites that could not be assessed endoscopically which are the preepiglottic space, the paraglottic space, thyroid cartilage, cricoid cartilage, hyoid bone and extra laryngeal tumor extension.

\section{Operative procedures:}

Among patients with supraglottic cancer treated surgically, 33 underwent total laryngectomy, 8 had supracricoid laryngectomy and 1 treated with supraglottic laryngectomy. Neck dissection was performed for all patients, $24(66.6 \%)$ had bilateral neck dissection and $12(33.3 \%)$ had unilateral neck dissection. Out of the 60 neck dissections performed, selective neck dissection (level II-IV) was done in 58 and 2 were radical neck dissection.

\section{Detailed histopathological assessment:}

Immediately following surgery the larynx was opened posteriorly to properly assess the primary tumour origin and local extension, the dissected lymph nodes previously marked and labeled intraoperatively were divided and each level was sent separately for histopathological examination. Examination started by measuring the tumor size and routine biopsies from the margins of the whole larynx specimen were taken to exclude invasion of the margins, long axial and sagittal sections were taken from the whole larynx specimen with particular focus on both the tumor main bulk and all previously stated sites of possible tumor extension. After fixation with formalin the obtained sections were furtherly cut into $2-3 \mathrm{~mm}$ serial sections that were stained with Hematoxylin and Eosin $(\mathrm{H} \& \mathrm{E})$, then examined to determine macroscopic and microscopic local invasion of various regions of the larynx, these regions were the same that were assessed endoscopically and radiologoically. Lymph nodes were extracted and counted from each neck node level delivered separately and were examined histopathologically for the presence of metastasis.

\section{Statistical analysis:}

Microsoft excel 2010 was used for data entry and the Statistical Package for Social Science (SPSS Version 21) was used for data analysis. Simple descriptive statistics (arithmetic mean and standard deviation) used for summary of quantitative data and frequencies used for qualitative data. Pearson chie square test was used for categorical variables. Wilcoxon signed rank test was used for statistical comparison between non-parametric variables.

\section{Results}

Among our 36 patients, 15 (36.7\%) had median supraglottic tumors, 12 (33.3\%) had lateral supraglottic tumors and in $9(25 \%)$ cases the tumor was marginal. 


\section{Clinical endoscopic assessment:}

In the analysis of exact tumor extension by clinical and endoscopic assessment it was found that vallecular involvement was noticed in 7 (19.4\%) cases. Anterior commissure involvement was found in $25(69.4 \%)$ cases and vocal fold involvement was found in $16(44.4 \%)$ cases where 12 were on the ipsilateral side and 4 were bilateral. Extension to the arytenoids was noted in $18(50 \%)$ cases and all were ipsilateral. Ipsilateral medial wall of pyriform sinus was found to be involved by the tumor in $12(33.3 \%)$ cases. Tongue base was found to be free in all cases by clinical and endoscopic assessment.

\section{Radiological assessment:}

Exact tumor extension by radiology reveled involvement of the base of tongue in $3(8.3 \%)$ cases, vallecula in $10(27.8 \%)$ cases, anterior commissure in $25(69.4 \%)$ cases, vocal fold in 17 (47.2\%) cases (13 ipsilateral and 4 bilateral), arytenoids in $16(44.4 \%)$ cases (all ipsilateral) and pyriform sinus medial wall in $15(41.7 \%)$ cases (14 ipsilateral and 1 bilateral). Preepiglottic space invasion was noted in $20(55.6 \%)$ cases, and paraglottic space invasion in $16(44.4 \%)$ cases $(13$ ipsilateral and 3 bilateral). Thyroid cartilage invasion was detected in $15(41.7 \%)$ cases and hyoid bone invasion was noted in $1(2.8 \%)$ cases.

\section{Pathological assessment:}

Detailed histopathological examination by whole organ section revealed involvement of base of tongue in $5(13.9 \%)$ cases, vallecula in 11 (30.6\%) cases, anterior commissure in $23(63.9 \%)$ cases, vocal fold in $19(52.2 \%)$ cases (15 ipsilateral and 4 bilateral) arytenoids in $15(41.7 \%)$ cases (all ipsilateral) and medial wall of pyriform sinus in $16(44.4 \%)$ cases. Involvement of preepiglottic space increased to $23(63.9 \%)$ cases and paraglottic space increased to $21(58.3 \%)$ cases (19 ipsilateral and 2 bilateral). Thyroid cartilage involvement increased to $18(50 \%)$ cases and hyoid bone involvement was the same as in radiology. Strap muscles was found to be involved by histopathology in $12(33.3 \%)$ cases. Table (1) shows the exact tumor extension to different sub sites by clinical, radiological and pathological assessment.

Table (1): Exact tumor extension to different sub sites by clinical, radiological and pathological assessment.

\begin{tabular}{|c|c|c|c|}
\hline Exact tumor extension & Clinical & Radiological & Pathological \\
\hline Base of tongue & 0 & $3(8.3 \%)$ & $5(13.9 \%)$ \\
\hline Vallecula & $7(19.4 \%)$ & $10(27.8 \%)$ & $11(30.6 \%)$ \\
\hline Preepiglottic space & NA & $20(55.6 \%)$ & $23(63.9 \%)$ \\
\hline Anterior commissure & $25(69.4 \%)$ & $25(69.4 \%)$ & $23(63.9 \%)$ \\
\hline Vocal folds & $\begin{array}{c}16(44.4 \%)\left\{\begin{array}{r}12 \text { ipsilateral } \\
4 \text { bilateral }\end{array}\right.\end{array}$ & $17(47.2 \%)\left\{\begin{array}{c}13 \text { ipsilateral } \\
4 \text { bilateral }\end{array}\right.$ & $19(52.8 \%)\left\{\begin{array}{c}15 \text { ipsilateral } \\
4 \text { bilateral }\end{array}\right.$ \\
\hline Paraglottic space & NA & 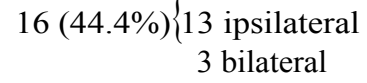 & $\begin{array}{c}21(58.3 \%)\{19 \text { ipsilateral } \\
2 \text { bilateral }\end{array}$ \\
\hline Arytenoids & $18(50 \%)$ all ipsilateral & $16(44.4 \%)$ all ipsilateral & 15 (41.7\%) all ipsilateral \\
\hline Thyroid cartilage & NA & $15(41.7 \%)$ & $18(50 \%)$ \\
\hline Hyoid bone & NA & $1(2.8 \%)$ & $1(2.8 \%)$ \\
\hline Pyriform sinus medial wall & $12(33.3 \%)$ all ipsilateral & $\begin{array}{cc}15(41.7 \%) & 14 \text { ipsilateral } \\
& 1 \text { bilateral }\end{array}$ & $16(44.4 \%)$ all ipsilateral \\
\hline Strap muscles & NA & 0 & $12(33.3 \%)$ \\
\hline Thyroid gland & NA & 0 & $1(2.8 \%)$ \\
\hline
\end{tabular}

NA: Not Applicable.

\section{Comparative analysis:}

On comparing clinical and radiological assessment there was increase in the tumour involvement of the following sites; base of tongue, vallecula, vocal fold and medial wall of pyriform sinus while anterior commissure involvement remained the same, on the other hand arytenoids involvement decreased. However the difference between clinical and radiological assessment was not found to be statistically significant. On comparing radiological and pathological assessment there was further increase in the involvement of the following sites; tongue base, vallecula, vocal folds and medial wall of pyriform sinus. Preepiglottic, paraglottic spaces and thyroid cartilage invasion increased by pathological examination, on the other hand anterior commissure involvement and arytenoid involvement decreased while hyoid bone invasion was the same by pathological examination. The 12 cases with strap muscle invasion were only detected by pathology. The percentage increase of invasion of the paraglottic space and strap muscles were the 
only variables that were statistically significant ( $p$-value $=0.025,0.001$ respectively).

On comparing clinical and pathological assessment base of tongue, vallecula and pyriform sinus were found to increase significantly statistically by pathological assessment $(p$-values $=0.025,0.046$,
0.046 respectively) and there was over estimation of anterior commissure and arytenoids invasion by clinical than by pathological assessment, however this difference was not statistically significant. Percentage of difference of involvement of the different sub sites by clinical, radiological and pathological examination is shown in (Table 2).

Table (2): Percentage of difference of involvement of different subsites by clinical, radiological and pathological examination.

\begin{tabular}{|c|c|c|c|c|c|c|c|c|c|}
\hline \multirow{2}{*}{ Subsite invaded } & \multicolumn{3}{|c|}{ Clinical vs. radiology } & \multicolumn{3}{|c|}{ Clinical vs. pathology } & \multicolumn{3}{|c|}{ Radiology vs. pathology } \\
\hline & No. & $\%$ change & $p$-vlaue & No. & $\%$ change & $p$-vlaue & No. & $\%$ change & $p$-vlaue \\
\hline Base of tongue & +3 & $8.3 \%$ & $0.083 \mathrm{NS}$ & +5 & $13.9 \%$ & $0.025 \mathrm{~S}$ & +2 & $5.6 \%$ & $0.157 \mathrm{NS}$ \\
\hline Vallecula & +3 & $8.3 \%$ & $0.083 \mathrm{NS}$ & +4 & $11.1 \%$ & $0.046 \mathrm{~S}$ & +1 & $2.8 \%$ & $0.317 \mathrm{NS}$ \\
\hline Preepiglottic space & NA & NA & NA & NA & NA & NA & +3 & $8.3 \%$ & $0.083 \mathrm{NS}$ \\
\hline Anterior commissure & 0 & $0 \%$ & $1 \mathrm{NS}$ & -2 & $5.6 \%$ & $0.157 \mathrm{NS}$ & -2 & $5.6 \%$ & $0.157 \mathrm{NS}$ \\
\hline Vocal folds & +1 & $2.8 \%$ & $0.37 \mathrm{NS}$ & +3 & $8.3 \%$ & $0.083 \mathrm{NS}$ & +2 & $5.6 \%$ & $0.157 \mathrm{NS}$ \\
\hline Paraglottic space & NA & NA & NA & NA & NA & NA & +5 & $13.9 \%$ & $0.025 \mathrm{~S}$ \\
\hline Arytenoids & -2 & $5.6 \%$ & $0.157 \mathrm{NS}$ & -3 & $8.3 \%$ & $0.083 \mathrm{NS}$ & -1 & $2.8 \%$ & $0.317 \mathrm{NS}$ \\
\hline Thyroid cartilage & NA & NA & NA & NA & NA & NA & +3 & $8.3 \%$ & $0.083 \mathrm{NS}$ \\
\hline Hyoid bone & NA & NA & NA & NA & NA & NA & 0 & 0 & $1 \mathrm{NS}$ \\
\hline Pyriform sinus medial wall & +3 & $8.3 \%$ & $0.083 \mathrm{NS}$ & +4 & $11.1 \%$ & $0.046 \mathrm{~S}$ & +1 & $2.8 \%$ & $0.317 \mathrm{NS}$ \\
\hline Strap muscles & NA & NA & NA & NA & NA & NA & +12 & $33.3 \%$ & $0.001 \mathrm{HS}$ \\
\hline Thyroid gland & NA & NA & NA & NA & NA & NA & +1 & $2.8 \%$ & $0.157 \mathrm{NS}$ \\
\hline
\end{tabular}

NA : Not Applicable.

NS : Not Significant.

$\mathrm{S}$ : Significant.

HS : Highly Significant

Wilcoxon signed ranks test was used for statistical analysis.

Regarding staging of the primary tumor by clinical and radiological assessment $2(5.6 \%)$ cases were classified as T2, $25(69.2 \%)$ cases as T3 and $9(25 \%)$ cases were T4a. Following detailed pathological assessment $\mathrm{T} 2$ cases increased to $3(8.3 \%)$ cases and T4a cases increased to $15(41.7 \%)$ cases while T3 cases decreased to $18(50 \%)$ cases. This difference in the staging between clinicoradiological classification and pathological classification was found to be statistically highly significant $(p$-value $=0.0001)$.

Regarding cervical nodal metastases clinical and radiological evaluation revealed $29(80.6 \%)$ cases to be N0 and $7(19.4 \%)$ cases showed positive nodal metastases, and upon postoperative pathological assessment the number of positive nodal metastases increased to $15(41.7 \%)$ and this was found to be statistically highly significant ( $p$-value $=$ 0.013 ). The difference between clinico-radiological nodal staging and pathological nodal staging was found to be statistically highly significant $(p$-value $=$ 0.006 ). The details of primary tumor staging and nodal involvement are shown in (Tables 3,4).
Table (3): The details of primary tumor staging and nodal involvement.

\begin{tabular}{llll}
\hline & Clinical radiological & Patholgical & PV \\
\hline$T:$ & & & \\
T1 & $0(0 \%)$ & $0(0 \%)$ & $0.0001 \mathrm{HS}$ \\
T2 & $2(5.6 \%)$ & $3(8.3 \%)$ & \\
T3 & $25(69.2 \%)$ & $18(50 \%)$ & \\
T4a & $9(25 \%)$ & $15(41.7 \%)$ & \\
$N:$ & & & \\
NO & $29(52.8 \%)$ & $21(58.3 \%)$ & $0.006 \mathrm{HS}$ \\
N1 & $2(5.6 \%)$ & $5(13.9 \%)$ & \\
N2a & $1(2.8 \%)$ & $1(2.8 \%)$ & \\
N2b & $3(8.3 \%)$ & $8(22.2 \%)$ & \\
N2c & $1(2.8 \%)$ & $0(0 \%)$ & \\
N3 & $0(0 \%)$ & $1(2.8 \%)$ & \\
\hline
\end{tabular}

HS: Highly Significant.

Pearson chie square test was used for statistical correlation.

Table (4): The details of primary tumor staging and nodal involvement.

\begin{tabular}{lccc}
\hline & Clinical radiological & Patholgical & PV \\
\hline No & $29(80.60 \%)$ & $21(58.3 \%)$ & $0.013 \mathrm{~S}$ \\
$\mathrm{~N}+\mathrm{ve}$ & $7(19.40 \%)$ & $15(41.7 \%)$ & \\
\hline
\end{tabular}




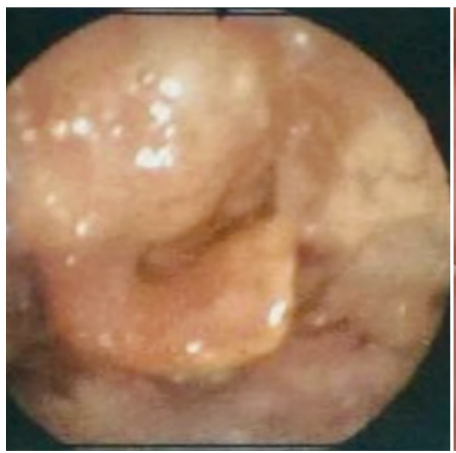

(A)

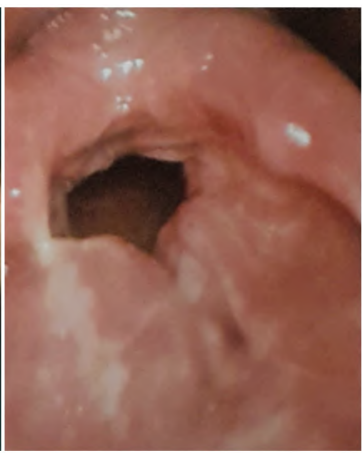

(B)

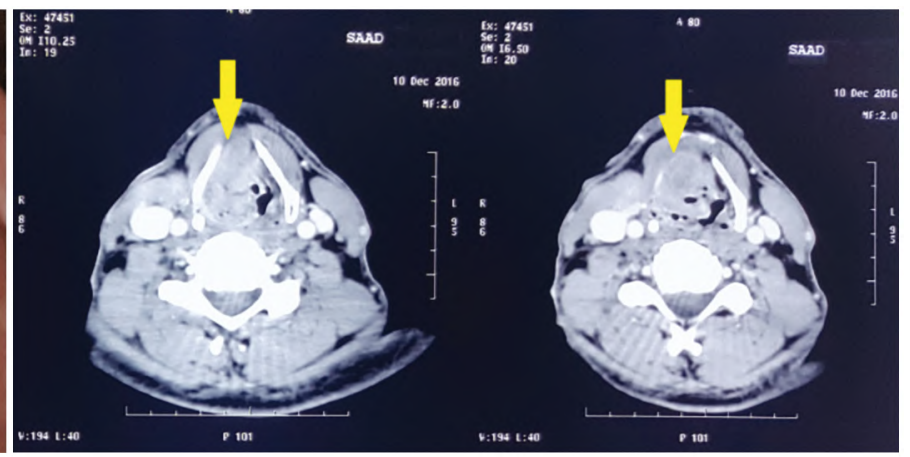

(C)

Fig. (1): (A) Flexible laryngoscopy showing a supraglottic tumor arising from the right aryepiglottic fold and extending medially to the ventricle, laterally to the medial wall of the pyriform fossa, anteriorly to the epiglottis and posteriorly to the arytenoid. (B) Flexible laryngoscopy showing a supraglottic tumor arising from the right ventricle and extending to the anterior commissure and the contralateral ventricle. (C) CT neck with contrast axial cuts showing supraglottic tumor arising from the right ventricle and invading the thyroid cartilage (yellow arrow).

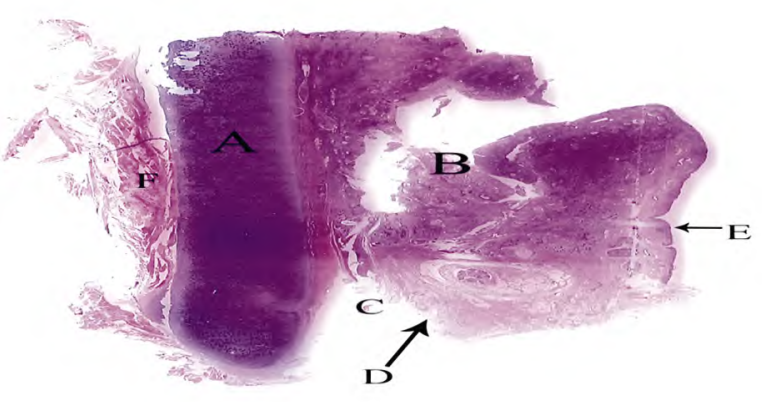

Fig. (2): Post laryngectomy whole organ axial section showing the main bulk of tumor (B) occupying the left paraglottic space, the left ventricle, the medial wall of the pyriform fossa and reaching but not invading the thyroid cartilage. (A) The left ala of thyroid cartilage. (C) The pyriform fossa. (D) The medial wall of the pyriform fossa. (E) The left ventricle. (F) The extralaryngeal muscle.

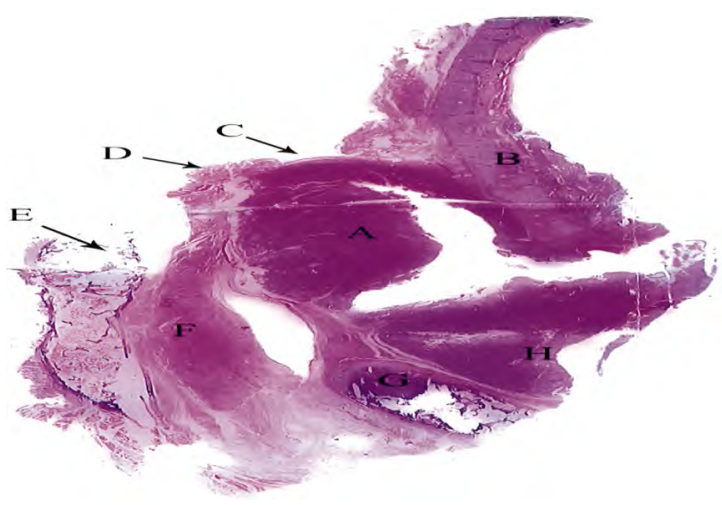

Fig. (4): Post laryngectomy whole organ sagittal section showing the main bulk of tumor (A) occupying the preepiglottic space and extending anteriorly and superiorly into the vallecula and tongue base but not reaching it. (B) The epiglottis. (C) The vallecula. (D) The tongue base. (E) The hyoid bone. (F) The thyrohyoid muscle. $(\mathrm{G})$ The The thyroid cartilage. $(\mathrm{H})$ Therest of the tumor extending towards the anterior commissure.

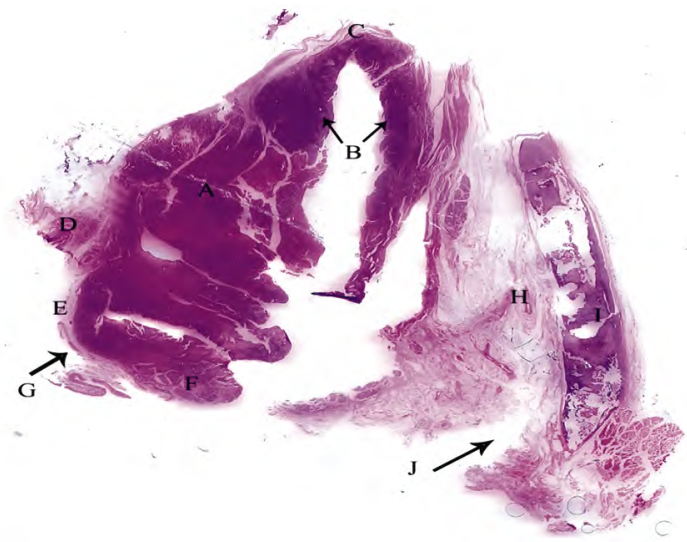

Fig. (3): Post laryngectomy whole organ axial section showing the main bulk of tumor (A) occupying the paraglottic space extending laterally into the paraglottic space, medially and anteriorly to the anterior commissure and contralateral ventricle, and posteriorly into the medial wall of the pyriform fossa, the arytenoid and the thyroid cartilage. (B) Right and left ventricles. (C) The anterior commissure. (D) The thyroid cartilage. (E) The medial wall of the pyriform fossa. (F) The arytenoid. $(\mathrm{G})$ The pyriform fossa. $(\mathrm{H})$ The contralateral paraglottic space. I. The contralateral thyroid cartilage ala. J. The contralateral pyriform.

\section{Discussion}

The proper management of supraglottic laryngeal cancer is dependent on accurate evaluation of the growth and spread within the larynx and neck lymph nodes. This is also important as the invasion of the sub sites within the larynx and cervical lymph node metastasis are of a great prognostic significance. In our study we sought to determine the patterns of local growth and spread of SGLC using whole organ serial sectioning along with radiological and endoscopic assessment.

The prognostic significance of pathological findings of laryngectomy specimens using whole organ sectioning and its impact on the loco-regional 
control was addressed in several previous studies [5-8]. However Serrano et al., reported insufficient studies correlating between cervical lymph node metastasis, tumor growth and spread in SGLC [9]

In our study whole organ serial sectioning has revealed more precise information about the involvement of the various sub sites within the larynx over endoscopic and radiological assessment among our 36 patients with SGLC.

In the analysis for comparing endoscopic and radiological assessment for the local spread of SGLC, radiological assessment was found to be slightly superior in the detection of invasion of the base of tongue, vallecula and medial wall of pyriform fossa with a percentage of increase by $8.3 \%$ without statistical significance. However radiological assessment did not show any superiority over the endoscopic assessment in the detection of invasion of vocal folds and arytenoids. The main value of radiological examination lies in the detection of thyroid cartilage involvement, invasion of the preepiglottic and paraglottic spaces as well as extension beyond the larynx [10]. In this study the radiological assessment revealed thyroid cartilage cartilage invasion in $41.7 \%$ ( 15 cases) and this increased to $50 \%$ (18 cases) by whole organ section pathology but still without statistical significance $(p=0.083)$. Weinstein et al., reported $45 \%$ thyroid cartilage invasion in supraglottic tumors [11]. In our study preepiglottic space and paraglottic space invasion increased by $8.3 \%$ and $13.9 \%$ respectively by whole organ section examination compared to radiological assessment with a statistical significance in the detection of paraglottic space invasion only $(p=0.025)$. Thus despite the sensitivity of radiology in detection of thyroid cartilage, preepiglottic space and paraglottic space invasion yet it could miss some cases particularly when assessing the paraglottic space. This is of utmost importance since invasion of the laryngeal spaces and thyroid cartilage may preclude the feasibility to do partial laryngectomy in supraglottic cancer, or may be associated with a high incidence of recurrence if partial laryngectomy would have been performed.

Dursun et al., upon evaluating preepiglottic space invasion in SGLC reported 10 out of 150 patients $(6.7 \%)$ with histological invasion of the preepiglottic space that was not detected by radiology [12]. Furthermore the paraglottic space is frequently involved in SGLC with preepiglottic space invasion [13,14]. This is due to the proximity of the preepiglottic to the paraglottic space at its postroinferior border. Therefore it may not be safe to perform limited endoscopic procedure or partial laryngectomy for supraglottic laryngeal tumor with undetected involvement of these sites. One of the critical sites for the evaluation is the pyriform sinus, in our study endoscopic assessment reveled 12 cases (33.3\%) with involvement of the pyriform sinus which increased by 3 cases $(8.3 \%)$ upon radiological examination and further by 1 case (2.8\%) upon whole organ examination. Therefore direct laryngoscopy may fail to assess submucosal growth of the tumor that could be detected radiologically as it is easier to evaluate exophytic tumor penetrating the mucosa by clinical assessment while it may miss underlying submucosal disease.

One of the significant findings in our study was the positive tumor deposits extra laryngeal in the strap muscles in 12 cases detected only by whole organ sectioning histology and this was statistically highly significant $(p=0.001)$. We consider this finding of utmost importance as total laryngectomy is the only surgical option in this situation.

Regarding the primary tumor staging, whole organ sectioning with detailed pathological examination significantly changed the primary tumor classification where 6 cases were upstaged from T3 to T4a and 1 case was down staged from T3 to $\mathrm{T} 2$. This significant change in the staging can be explained by the significant underestimation of involvement of the paraglottic space and strap muscles by clinical and radiological assessment observed in our study.

\section{References}

1- LIBERA D.D.: Pattern of Spreading of Larynx Cancer. In: Marco L, eds. Practical guide to neck dissection. Focusing on the larynx. Berlin, Heidelberg: Springer Berlin Heidelberg: 157-85, 2013.

2- THEKDI A.A. and FERRIS R.L.: Dignostic assessment of laryngeal cancer. Otolaryngol. Clin. North Am., 35 (5): 953-69, 2002.

3- YOUSEM D.M., GAD K. and TUFANO R.P.: Resectability issues with head and neck cancer. A.J.N.R. Am. J. Neuroradiol., 27 (10): 2024-36, 2006.

4- KIM J.W., YOON S.Y., PARK I.S. and KIM Y.M.: Correlation between radiological images and pathological results in supraglottic cancer. J. Laryngol. Otol., 122 (11): 1224-9, 2008.

5- ZEITELS S.M. and VAUGHAN C.W.: Preepiglottic space invasion in early epiglottic cancer. Ann. Otol. Rhinol. Laryngol., 100 (10): 789-92, 1991.

6- ZBAREN P., NUYENS M., CURSCHMANN J. and STAUFFER E.: Histologic characteristics and tumor spread of recurrent glottis carcinoma: Analysis on whole organ sections and comparison with tumor spread of primary glottic carcinomas. Head Neck, 29 (1): 26-32, 2007. 
7- CHIJIWA H., SATO K., UMENO H. and NAKASHIMA T.: Histopathological study of correlation between laryngeal space invasion and lymph node metastasis in glottic carcinoma. J. Laryngol. Otol., Suppl (31): 48-51, 2009.

8- MUTLU V., UCUNCU H., ATLAS E. and AKTAN B.: The relationship between the localization, size, stage and histopathology of the primary laryngeal tumor with neck metastasis. Eurasian J. Med., 46 (1): 1-7, 2014.

9- SERRANO M.G., IGLESIAS. MORENO M.C., GIMENO HERNANDEZ J., ORTEGA MEDINA L., MARTIN VњLARIS C. and POCH BROTO J.: Cartilage invasion patterns in laryngeal cancer. Eur. Arch. Otorhinolaryngol., 273 (7): 1863-9, 2016.

10- LICITRA L., BERNIER J., GRANDI C., LOCATI L., MERLANO M., GATTA G., et al.: Cancer of the larynx. Crit. Rev. Oncol. Hematol., 47 (1): 65-80, 2003.
11- WEINSTEIN G.S., LACCOURREYE O., BRANSU D. TUCKER J. and MONTONE K.: Reconsidering a paradigm: The spread of supraglottic carcinoma to the glottis. Laryngoscope, 105: 1129-33, 1995.

12- DURSUN G., KESER R., AKTURK T., AKINER M.N., DEMIRELLER A. and SAK S.D.: The significance of pre-epiglottic space invasion in supraglottic laryngeal carcinomas. Eur. Arch. Otorhinolaryngol., 254 (Suppl. 1): S110-S2, 1997.

13- BOCCA E., PIGNATARO O. and MOSCIARO O.: Supraglottic surgery of the larynx. Ann. Otol. Rhinol. Laryngol., 77: 1005-25, 1968.

14- SATO K., KURITA S. and HIRANO M.: Location of the preepiglottic space and its relationship to the paraglottic space. Ann. Otol. Rhinol. Laryngol., 102: 930-4, 1993.

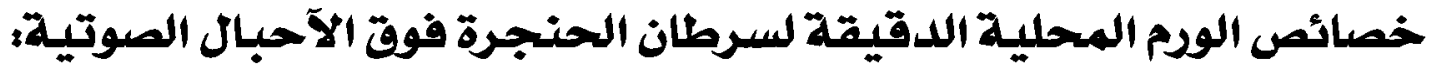

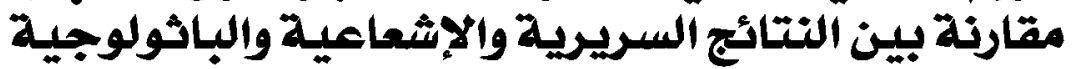

\author{
الهدف: تحديد الإمتداد الدقيق للسرطان الخلايا الحرثفية فوق الشبكية عن طريق تقطيع الآعضاء بآكملها ومقارنتها بالنتائج الإشعاعية \\ والمنظارية. \\ المواد والطرق: شملت هذه الدراسة بr مريضا يعانون من سرطان الحنجرة الناشئ من الحنجرة فوق الآحبال الصوتية. تم إجراء تنظير

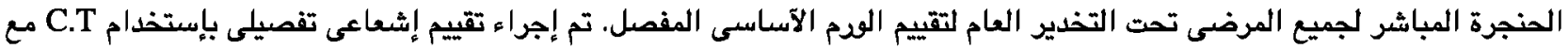

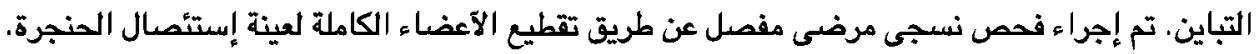

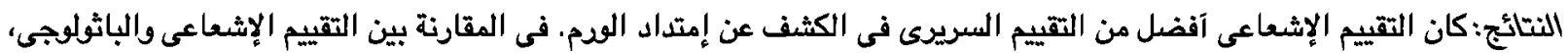 \\ كانت النسبة المئوية لزيادة غزو الفضاء الجار آحبال صوتية وعضلات الحزام هي المتفيرات الوحيدة التى كانت ذات دلاتلاتلة إحصائية

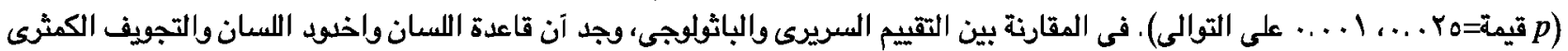

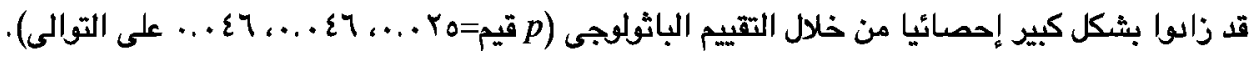

